\author{
UNIVERSIDADE DE SÃO PAULO \\ FACULDADE DE CIÊNCIAS FARMACÊUTICAS DE RIBEIRÃO PRETO
}

\title{
Caracterização molecular de proteínas de roptrias (ROP15B e ROP55) de Neospora caninum
}

\begin{abstract}
Dissertação de Mestrado apresentada ao Programa de Pós-Graduação em Biociências Aplicadas à Farmácia para obtenção do Título de Mestre em Ciências.
\end{abstract}

Área de Concentração: Biociências Aplicadas à Farmácia.

Orientada: Julia Audrey de Paula

Orientadora: Profa. Dra. Ana Patrícia Yatsuda Natsui

Versão corrigida da Dissertação de Mestrado apresentada ao Programa de PósGraduação em Biociências Aplicadas à Farmácia em 19/11/2018 (Data da Defesa). A versão original encontra-se disponível na Faculdade de Ciências Farmacêuticas de Ribeirão Preto/USP. 


\section{Resumo}

DE PAULA, J. A. Caracterização molecular de proteínas de roptrias (ROP15B e ROP55) de Neospora caninum. 2018. 57f. Dissertação (Mestrado). Faculdade de Ciências Farmacêuticas de Ribeirão Preto - Universidade de São Paulo, Ribeirão Preto, 2018.

Neospora caninum (Apicomplexa) é o agente causador da neosporose, descrita como a principal causa de aborto parasitário em gado bovino .Parasitos desse filo interagem e invadem as células hospedeiras através da secreção coordenada de proteínas do complexo apical, formado por diversas organelas, dentre elas as roptrias (ROPs), que desempenham papel fundamental no processo de infecção, associado à formação do vacúolo parasitóforo (PV), sobrevivência no ambiente intracelular e virulência do parasito. Essas proteínas podem ser caracterizadas em: proteínas de roptrias de pescoço (RONs), e proteínas de roptrias (ROPs). Além disso, algumas ROPs podem se diferenciar e, dessa maneira, constituem uma grande família de quinases e pseudo-quinases, denominada família de roptrias quinase (ROPKs). O objetivo deste estudo foi caracterizar as proteínas de roptrias NcROP15B (NcLIV_011700) e NcROP55 (NcLIV_031550) de N. caninum. As sequências de NcRŌP15B e NcROP55 foram alinhadas com homólogos de alguns microrganismos, incluindo apicomplexas, ao BLAST. NcROP15B apresentou identidade de $19 \%$ com as sequencias de ROP15 de T. gondii e Hammondia hammondi. NcROP55 mostrou identidade de 14\% com a ROP37 de T. gondii e com ROP28 de Hammondia hammondi, e 15\% com a ROP28 de Neospora caninum. Foram detectados domínios pertencentes à família de proteínas quinase para NcROP15B e NcROP55, e peptídeo sinal apenas para NcROP15B. Os primers foram delineados para amplificar regiões de cDNA de ambos os genes com diferentes tamanhos, denominados NcROP15B maior, NcROP15B menor, NcROP55 maior e NcROP55 menor. Os insertos foram subclonados (pGEM) e posteriormente ligados em plasmídeo de expressão pET28 em E. coli BL21(DE3) e a expressão recombinante induzida por IPTG. As formas recombinantes foram expressas com 30 kDa e 16 kDa (NcROP15B fragmento Maior e Menor, respectivamente) e NcROP55 Maior e Menor gerou um peso molecular de 19.9 kDa e 15 kDa, respectivamente. Após purificação, NcROP15B e NcROP55 foram utilizadas para obtenção de soros policlonais. Anti-ROP15B e anti-ROP55 reagiram com extrato de $N$. caninum em Western Blot 1D, tendo NcROP15B sido detectada com $35 \mathrm{kDa}$, próximo ao predito (32 kDa) e NcROP55 com aproximadamente $35 \mathrm{KDa}$, porém abaixo do predito (47.9 kDa). Na imunofluorescência confocal, NcROP-15B e NcROP55 exibiram padrão de localização na região perinuclear de taquizoítos de $N$. caninum. Os anticorpos antiNcROP15B e anti-NcROP55 apresentaram, individualmente, capacidade limitada para inibir o processo de adesão/invasão de $N$. caninum, sendo $16 \%$ e $6,43 \%$ respectivamente. Quando os soros anti-NcROP15B e anti-NcROP55 foram associados, a a inibição da invasão aumentou para 62\%. As proteínas NcROP-15B e NcROP55 podem representar quinases importantes no metabolismo de $N$. caninum, e podem estar relacionadas ao processo de invasão e proliferação do parasito. Dessa maneira, são possíveis alvos para se considerar no estudo de medidas preventivas, sendo necessários mais estudos para avaliar suas funções na sobrevivência intracelular e virulência de $N$. caninum.

Palavras-chave: Neospora caninum, roptrias, invasão celular, proteínas quinases, NcROP15B, NcROP55 


\section{INTRODUÇÃO}

Neospora caninum (N. caninum) é um protozoário do filo Apicomplexa, da família Sarcocystidae (DUBEY et al., 1988). Esse parasito é agente causador da doença neosporose que acomete alguns animais, tais como: bovinos, cães, ovinos, porcos, caprinos, búfalos, aves e equinos (DUBEY; SCHARES, 2011). O filo constitui de muitos parasitos que são patógenos para seres humanos e animais, como Toxoplasma gondii (agente da toxoplasmose) (MONTOYA; LIESENFELD, 2004), Plasmodium falciparum (responsável pela malária) (SNOW et al., 2005) e Eimeria tenella (responsável pela coccidiose de galinhas) (WALLACH, 2010).

Antes de ser descoberto, $N$. caninum foi previamente confundido com $T$. gondii, por apresentar características biológicas e um ciclo de vida heteroxênico bem semelhantes (MARK et al., 1999). Porém, no final da década de 80 , o parasito foi isolado, cultivado e nomeado por Dubey e colaboradores como uma nova espécie (DUBEY et al., 1988). A infecção por $N$. caninum pode acontecer por via horizontal, com a ingestão de oocistos liberados pelos hospedeiros definitivos (canídeos), e também por via vertical (transmissão transplacentária), que ocorre em hospedeiros intermediários, (com destaque para os bovinos) (Figura 1). A transmissão vertical requer atenção, pois resulta em abortos ou perdas reprodutivas, causando prejuízo às indústrias de carne e laticínios. (DONAHOE et al., 2015; DUBEY, 1999; LEINEWEBER et al., 2017; REICHEL et al., 2013).

Durante o desenvolvimento do parasito é possível observar três formas fundamentais: taquizoítos, bradizoítos e esporozoito (DUBEY, 2003). Oocistos não esporulados são formas liberadas nas fezes pelos hospedeiros definitivos que se infectam ao se alimentarem de carne contaminada (REICHEL et al., 2007). Estes oocistos esporulam no ambiente e podem ser ingeridos pelos hospedeiros intermediários, tais como gado (Figura 1a). No interior do tubo digestivo do hospedeiro intermediário, os esporozoítos se desenvolvem para taquizoítos (Figura 1b) (HEMPHILL et al., 2006). Os taquizoítos replicam rapidamente dentro do vacúolo parasitóforo, podendo invadir e infectar eficazmente uma variedade de células hospedeiras (Figura 1e) (BARR et al., 1993; DUBEY et al., 2002). Então taquizoítos são diferenciados em bradizoítos, que residem durante a fase crônica em tecidos e órgãos (Figura 1f) (DUBEY et al., 1990; DUBEY; SCHARES, 2011). Finalmente, estes cistos teciduais podem ser transmitidos para os hospedeiros definitivos através 
de carne contaminada, completando o ciclo horizontal (transmissão pós-natal) (Figura 1f) (MCALLISTER et al., 1998; REICHEL et al., 2013).

Figura 1. Ciclo de vida heteroxênico de $\boldsymbol{N}$. caninum. O ciclo de vida heteroxênico deste parasita inclui uma replicação sexuada (que ocorre no canídeo: hospedeiro definitivo) e uma reprodução assexuada no hospedeiro intermediário (representado nesse caso pelo bovino). (A) No hospedeiro intermediário, a infecção pode ocorrer horizontalmente através da ingestão de alimentos ou água contaminada com oocistos contendo esporozoítos previamente liberados nas fezes de canídeos infectados agudamente; ou (B) verticalmente da mãe para o feto através da placenta (GOODSWEN et al., 2013). (C) Após a fase de proliferação rápida, $N$. caninum diferencia-se no estágio de bradizoítos que residem nos cistos teciduais intracelulares, estabelecendo infecções de longos períodos (PIERGILI FIORETTI et al., 2003). (D) Durante a gestação, modificações na resposta imune da mãe favorecem a reativação do parasito e a reconversão de bradizoítos em taquizoítos, os quais podem atravessar a placenta e gerar uma infecção fetal (INNES, 2007). (E) A reativação de uma infecção persistente com transmissão vertical pode ocorrer sobre gestações consecutivas e pode resultar em aborto ou no nascimento de bezerros saudáveis, mas congenitamente infectados (WILLIAMS et al., 2009). (F) Por fim, o ciclo de vida é completado quando cistos teciduais contendo bradizoítos, presentes nos tecidos do hospedeiro intermediário, são ingeridos por um hospedeiro definitivo carnívoro.

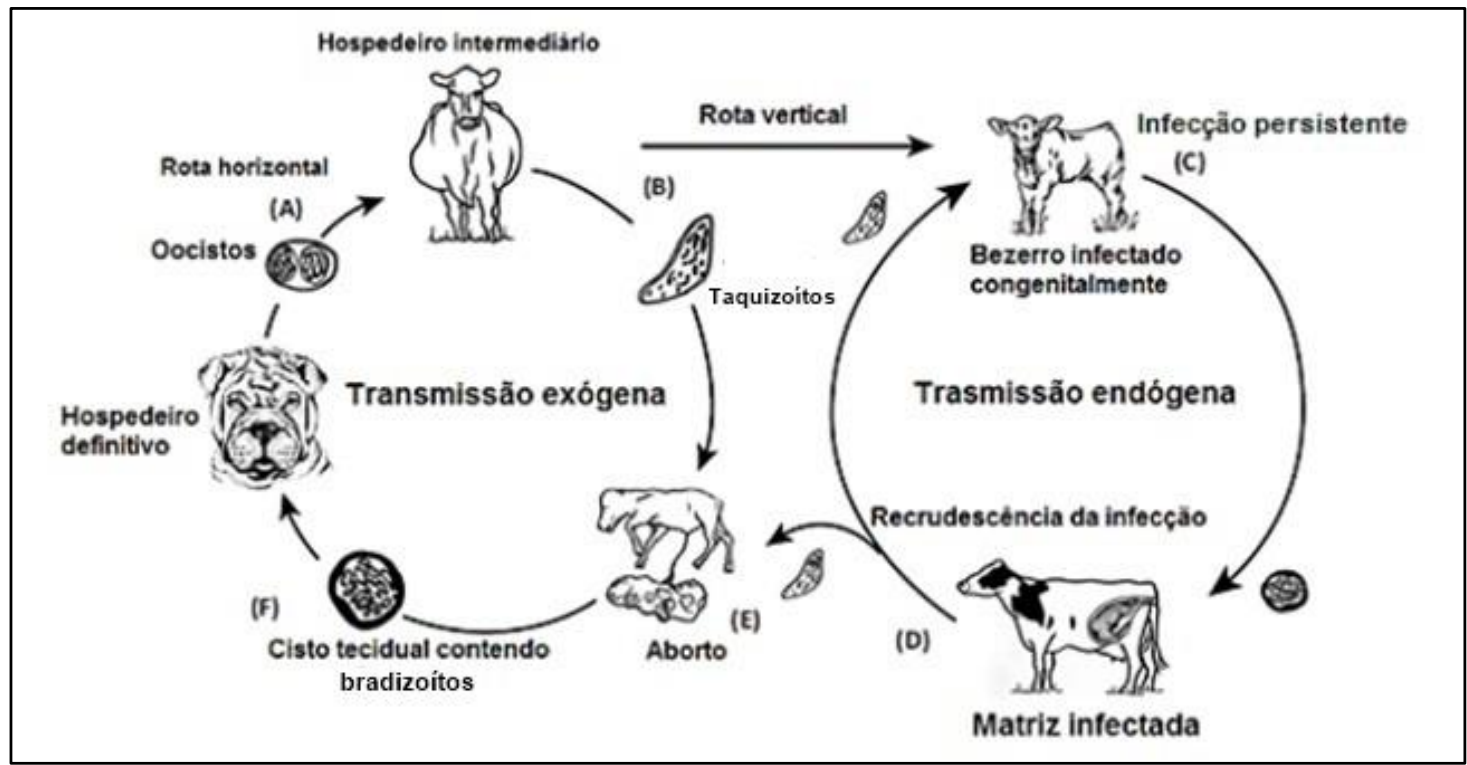

Fonte: Adaptado de GUIDO et al. (2016).

$\mathrm{Na}$ via vertical, os taquizoítos do animal infectado são transmitidos para o feto através da placenta, contribuindo dessa maneira para a persistência da infecção por N. caninum no bovino, propagando a infecção para futuras gerações (Figura 1d) (BARR et al., 1993; SCHARES et al., 1998; HIETALA; THURMOND, 1999) e sendo uma das principais causas de aborto parasitário em gado leiteiro e a principal forma de transmissão da doença (Figura 1e) (DUBEY; SCHARES, 2011; LEINEWEBER et al., 2017).

Por se tratar de um parasito intracelular obrigatório, a sobrevivência e a proliferação dos estágios "zoítos" de $N$. caninum dependem do interior da célula 
hospedeira. Sendo assim, compreender os processos de invasão da célula hospedeira, assim como o desenvolvimento intracelular do parasito, representa uma importante abordagem para se aplicar alguma estratégia no controle da neosporose, quer por vacinas ou quimioterapia (HEMPHILL et al., 2013). Além disso, os processos fundamentais da invasão do parasito na célula hospedeira permanecem bastante conservados, pois o filo é caracterizado pela presença de características comuns responsáveis pela interação entre parasito e célula hospedeira. Estas incluem componentes de um conjunto de organelas secretoras denominado de complexo apical, o qual é composto por micronemas grânulos densos e roptrias localizados na extremidade apical do parasita (Figura 2) (BAUM et al., 2006). Neste contexto, grande parte das investigações moleculares desse filo, tem sido realizada em T. gondii, que representa um modelo chave entre os membros do grupo (CARRUTHERS; BOOTHROYD, 2007).

Figura 2- Representação morfológica das formas evolutivas taquizoíto de Toxoplasma e merozoíto de Plasmodium falciparum. O complexo apical, sendo uma característica de definição de membros do filo Apicomplexa, é composto de anéis polares, micronemas, roptrias e, em alguns casos, conóide.

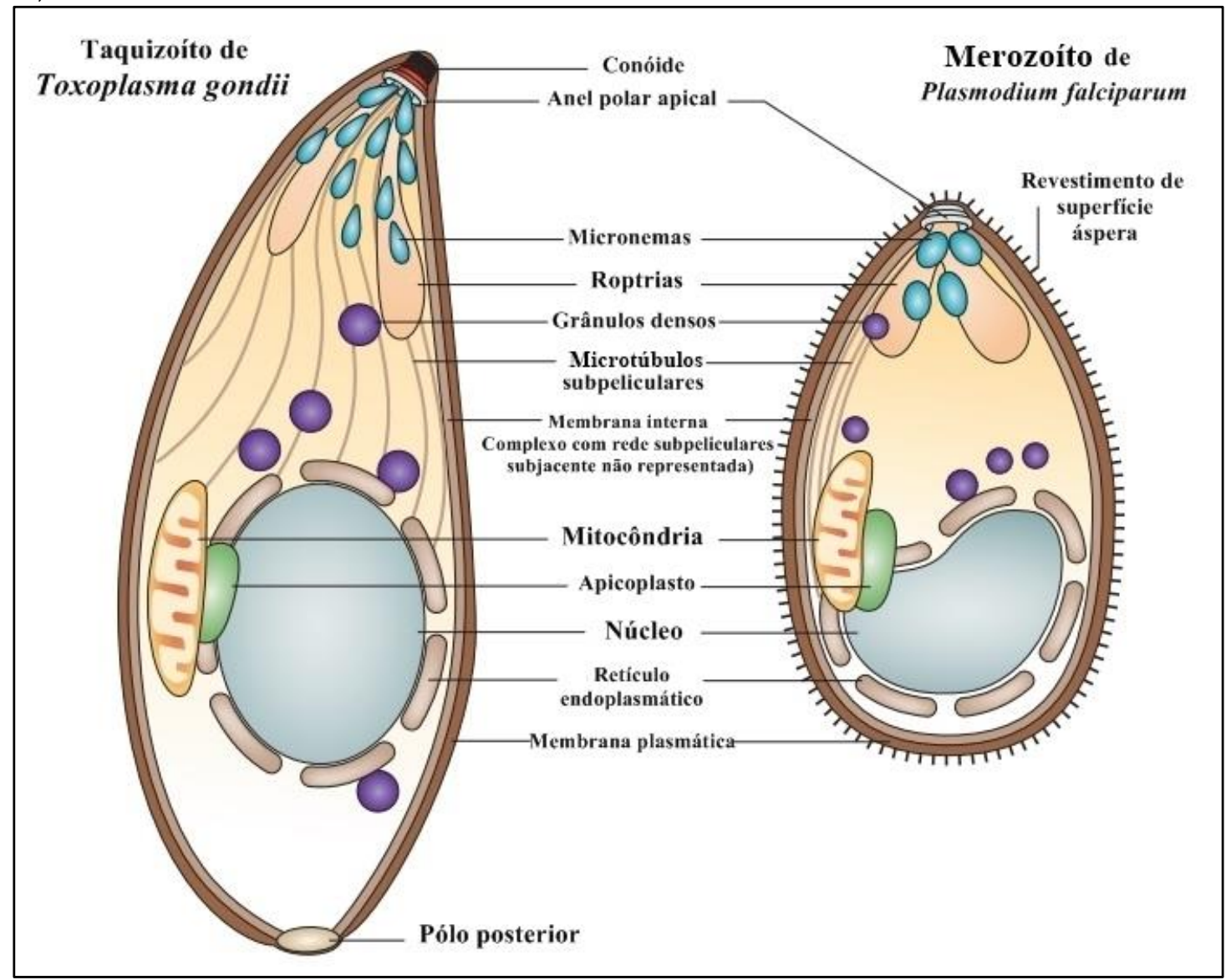

Fonte: Adaptado de BAUM et al (2006). 
Por ser um parasito "jovem", os estudos com N. caninum começaram bem tardiamente, quando comparado com outros parasitos do filo, como $T$. gondii, Cryptosporidium spp, Eimeria spp, Plasmodium spp e Theileria spp (DUBEY,2007). Os trabalhos abrangem no geral investigações epidemiológicas, diagnóstico e exames de expressão e localização de genes clonados, além de questões sobre a imunogenicidade do parasito. Em relação às proteínas desse parasito há escassez de dados com estudos funcionais (HAMMOUDI et al., 2015; HUl et al., 2014; LI et al., 2016; SHEN et al., 2014a, WILLIAMS et al., 2015).

No Brasil, já foram encontrados anticorpos anti-Neospora spp. em canídeos nas cinco regiões do país, tanto de áreas rurais como das áreas urbanas (SNAK et al., 2018; RAIMUNDO et al., 2015; LANGONI et al., 2014; SICURPIRA et al., 2012; BENETTI et al., 2009). O mesmo se verificou para bovinos, os quais têm grande importância econômica no país, devido à produção de carne e leite (SNAK et al., 2018; RAMOS et al., 2016; CARDOSO et al., 2012; BENETTI et al., 2009; AGUIAR et al., 2006). Considerando os búfalos, foi observado uma ocorrência de anticorpos anti- $N$. caninum variando de $14,6 \%$ a $88 \%$, porém não há relatos de prejuízo reprodutivo nesses animais (GENNARI et al., 2005; GONDIM et al., 2007). Pesquisas também verificaram alta soro prevalência do parasito em ovelhas, com uma taxa de transmissão vertical de 11\% (em um grupo de nove animais, uma ovelha gerou duas infectadas) (FILHO et al., 2017). Anticorpos anti-N. caninum não são detectados apenas em ruminantes, mas há evidências de doença em diversos outros hospedeiros intermediários, animais de sangue quente, como jaguatirica, galinhas domésticas, porcos, entre outros animais (ANDRÉ et al. 2010; COSTA et al., 2008; GONDIM et al., 2010; SOARES et al., 2016).

\subsection{Invasão da célula do hospedeiro pelo parasito do Filo Apicomplexa}

O processo de invasão é composto de múltiplos passos de modo ativo e rápido que leva à formação de um vacúolo parasitóforo (VP), onde o parasito sobrevive e se prolifera (BRECHT et al., 2001). No início desse processo, os parasitos do filo Apicomplexa migram até seu local de preferência e invadem a célula hospedeira através de uma forma especial de movimento chamado motilidade por gliding. Este movimento é impulsionado por um sistema de actina-miosina que ajuda os parasitos a impelir-se para a célula hospedeira (FRENAL et al., 2010). 
O processo de invasão é completado em, pelo menos em sete passos (Figura 3) a partir de ligação inicial até a entrada definitiva no interior da célula hospedeira (CARRUTHERS E BOOTHROYD, 2007). Em um primeiro momento, um contato reversível de baixa afinidade entre parasito e a membrana de superfície da célula hospedeira é estabelecido pela família das Proteínas de Superfícies Relacionadas à SAG (SRS). Em seguida o conteúdo das organelas filo específicas (micronemas e roptrias) é secretado, com liberação das proteínas micronêmicas (MIC) e de roptrias (RON e ROP). Diversas das proteínas envolvidas neste processo foram identificadas e caracterizadas em $T$. gondii, cujos estudos permitiram a construção do modelo de invasão celular da Figura 3 (BURG et al., 1988; PARMLEY et al., 1992, CESBRONDELAUW et al., 1994; HEHL et al., 1997; MACEDO et al., 2013) e N. caninum (HEMPHILL, 1996; NISHIKAWA et al., 2000; NISHIKAWA et al., 2001; HALDORSON et al., 2006;. ROCCHI et al., 2011; SOHN et al., 2011).

Figura 3 - Etapas no processo de invasão do Apicomplexa Toxoplasma gondii. O processo multifatorial se inicia com o reconhecimento pelas proteínas de superfície do taquizoíta (ex. SAG 1) e hospedeiro (1). A liberação das proteínas micronêmicas (MICs) possibilita a ligação entre ligantes e o motor de actina/miosina (MyoA) (2). O início da invasão ocorre com a interação entre as proteínas das roptrias (RONs e ROPs) e AMA 1, formando a junção de movimento (MJ, 3) e o vacúolo parasitóforo (4 e 5). Por fim o parasita é liberado da junção pela clivagem das proteínas micronêmicas pelas rombóides (ROMs) (6 e 7).

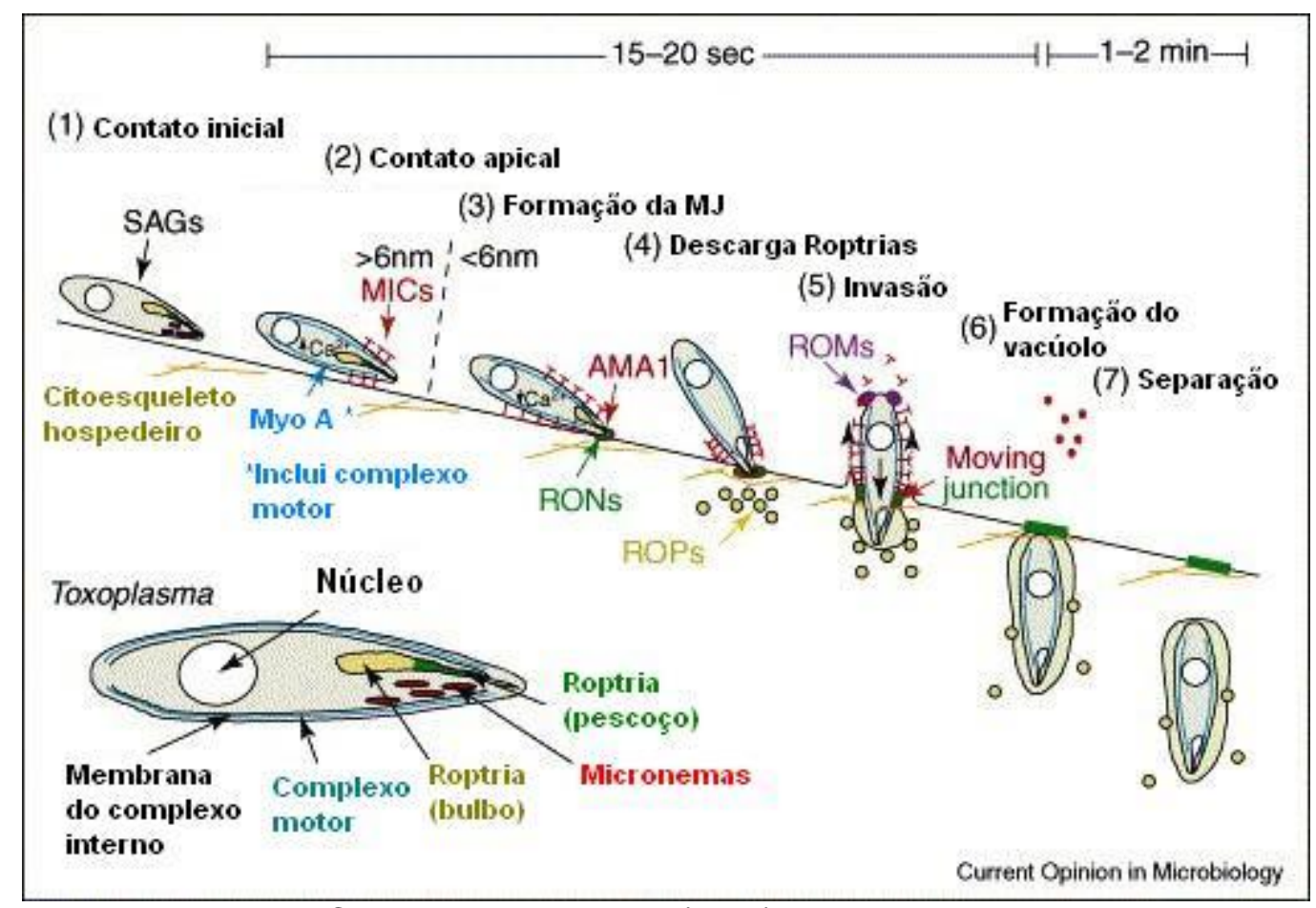

Fonte: Adaptado de Carruthers e Boothroyd (2007) 
Após o contato inicial, quando o nível do cálcio intracelular no interior do parasito aumenta (CARRUTHERS; SIBLEY, 1999), as proteínas são liberadas a partir de micronemas. Estas pequenas vesículas chamadas MICS, se aglomeram na porção apical da zoíto e secretam rapidamente um grande número de proteínas quando o contato inicial é feito entre o parasito e a célula hospedeira, atuando como principais fatores de adesão celular às células hospedeiras e participam do reconhecimento do parasito, reorientação e receptores de células hospedeiras (CARRUTHERS; TOMLEY, 2008; BILLKER et al., 2009; SANTOS et al., 2012).

Proteínas de roptrias de pescoço são então liberadas de forma regulada na porção anterior do parasito, para formar uma região apertada de contato com a célula hospedeira. Dessa forma é possível a formação de um complexo estável com a membrana da célula do hospedeiro, conhecida como junção de movimento (MJ), o qual atua como um andaime para que o parasito entre na célula, resultando na formação do vacúolo parasitóforo (VP) aonde o parasito irá residir e se multiplicar (ALEXANDER et al., 2005; CARRUTHERS; BOOTHROYD, 2007; HEINTZELMAN, 2015). As roptrias também liberam uma variedade de proteínas que modulam a função da célula hospedeira (EL HAJJ et al., 2007; ONG et al., 2010; SINAI; JOINER, 2001), e que estão relacionadas com a virulência do parasito e as células de defesas do hospedeiro.

Durante a formação do $M J$, as proteínas do bulbo de roptrias (ROP) são injetadas dentro do citoplasma da célula hospedeira no local de invasão. Algumas ROP ficam ligadas às pequenas vesículas destinadas a fundir-se com o desenvolvimento da membrana do vacúolo parasitóforo (MPV), enquanto outras ROP solúveis são descarregadas para dentro da célula hospedeira. Enquanto o parasito invade a célula hospedeira, complexos MIC transmembranas são também deslizados para a extremidade posterior do parasito e são clivados por proteases intramembranas denominadas rombóides. Quando o parasito invagina a membrana da superfície da célula hospedeira, o vacúolo parasitóforo está completamente formado, podendo atravessar o citoesqueleto do hospedeiro separando-se da membrana plasmática do hospedeiro para completar o processo de invasão (CARRUTHERS; BOOTHROYD, 2007). Apesar da preservação relativa dos mecanismos de invasão através do filo, existem algumas diferenças. Por exemplo, Theileria spp representa um modo muito diferente da invasão da célula hospedeira. Os "zoitas" da Theileria que são não móveis na natureza invadem o hospedeiro por 
um mecanismo irreversível ("zippering"), em vez de uma invasão ativa dependente de glideosoma. Além disso, não há orientação apical de zoita e não há proteínas micronêmicas, sendo necessárias proteínas adesivas para a invasão de zoitas em Theileria (KEMP et al., 2013).

\subsection{Papéis das roptrias na invasão celular do hospedeiro}

As roptrias são organelas específicas do filo Apicomplexa com formato de bulbo na base e afinando no pescoço (LEMGRUBER et al., 2011). Essas organelas secretam proteínas que contribuem na invasão, na sobrevivência do parasito na célula hospedeira e em alterar processos nessas células. Durante a invasão, a membrana do VP é formada a partir da membrana plasmática do hospedeiro em conjunto com as proteínas segregadas a partir das roptrias (BESTEIRO et al., 2009). Essas proteínas podem ser organizadas em duas classes, as das proteínas de roptrias de pescoço (RONs) e as proteínas de roptrias (ROPs), que atuam em momentos distintos durante o processo de invasão celular. As proteínas de roptrias de pescoço (RONs) estão localizadas na parte mais fina da organela e estão envolvidas na formação e função da junção de movimento, conforme ilustrado na figura 3 (itens 4 e 5) (ALEXANDER et al., 2005; BECK et al. 2014). Já as roptrias que estão localizadas no compartimento do bulbo, são denominadas de proteínas de roptrias (ROPs) e são secretadas posteriormente no vacúolo parasitóforo recémformado ou na célula hospedeira (Figura 4) (CARRUTHERS; SIBLEY, 1997). Algumas ROPs ainda podem se diferenciar e participar de uma grande família de quinases e pseudo-quinases, as chamadas família de roptrias quinase (ROPKs), uma classe de enzimas que regulam a transdução do sinal celular por meio da fosforilação e já que foram evidenciadas em diversos organismos do filo Apicomplexa. 
Figura 4. Proteínas de pescoço de roptrias e proteína de roptrias (RONs e ROPs, respectivamente) durante e após a invasão em Plasmodium spp. As proteínas de roptrias de pescoço (RONs) localizam-se predominantemente no local de adesão da superfície do merozoíto ou na junção apertada (TJ) durante a fixação e a invasão, embora a função e a localização final de vários RONs permaneçam desconhecidas. As proteínas de roptrias (ROPs) são secretadas após o parasito ter entrado completamente no eritrócito, e podem estar envolvidas na formação da membrana do vacúolo parasitóforo.

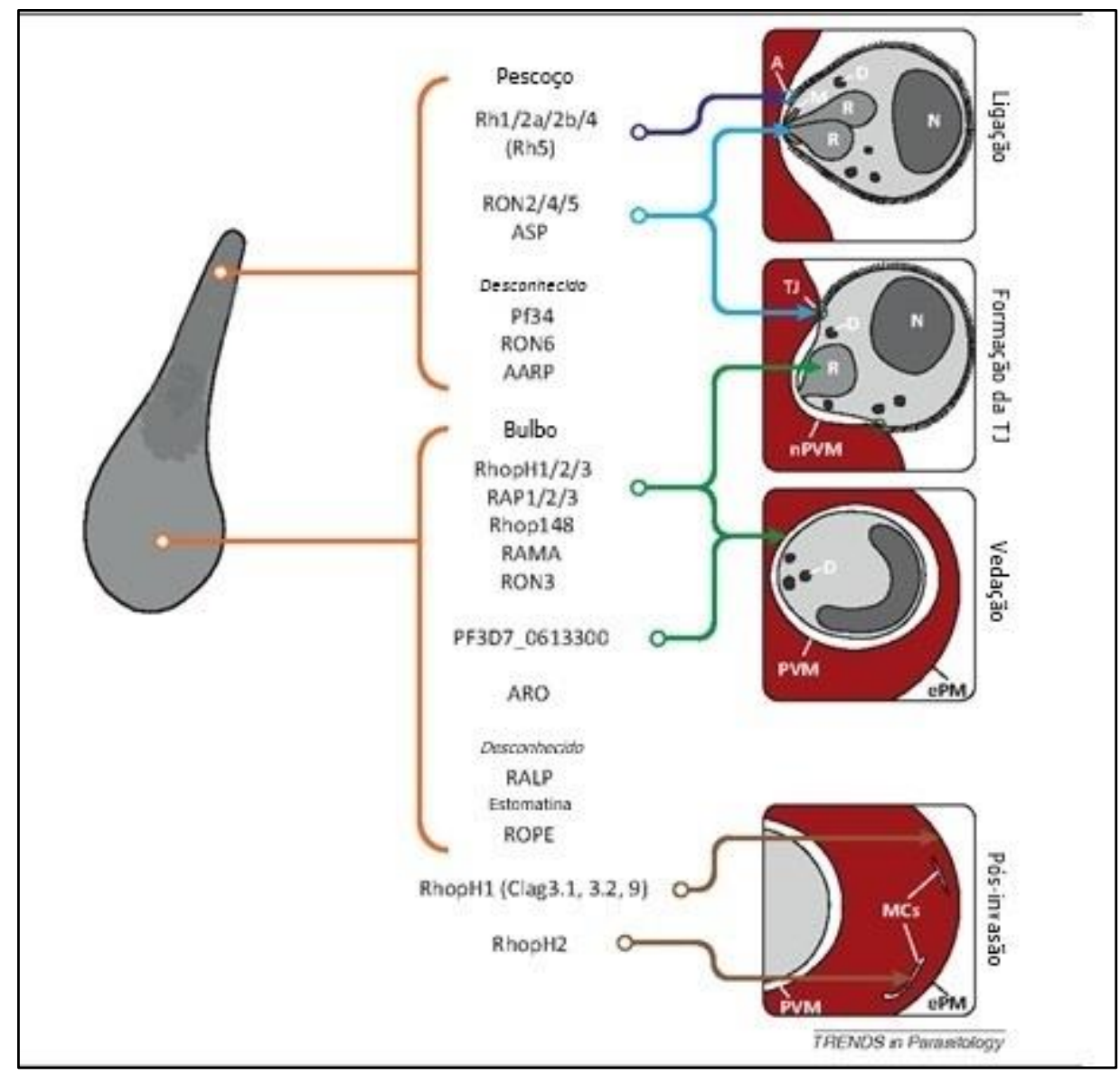

Fonte: Adaptado de COUNIHAN et al (2013).

Em 2013, Talevich e Kannan catalogaram e compararam, através de uma extensa análise in silico, a superfamília de roptrias quinases dos genomas de $T$. gondii, N. caninum, Sarcocystis neurona e Eimeria tenella, delineando assim, uma árvore filogenética a partir das sequências de consenso de cada uma das subfamílias da ROPK para ilustrar o padrão evolucionário na família ROPK em vários Apicomplexa (Figura 5) (BRADLEY; SIBLEY, 2007; PEIXOTO et al., 2010). 
Figura 5. Filogenia das subfamílias de roptrias quinases de T. gondii, $N$. caninum, Sarcocystis neurona e Eimeria tenella. As proteínas de roptrias quinases preditas ou conhecidas são marcadas em negrito, e quinases que podem ter um mecanismo catalítico não-canônico são marcadas com um asterisco. As subfamílias ROPK recentemente propostas são rotuladas em texto itálico. O clado indicado em vermelho contém as subfamílias da ROPK com uma extensão do terminal $\mathrm{N}$ homóloga ao domínio da quinase (NTE). O clado em verde é específico para E. tenella. O clado divergente "ROPKL" é mostrado em azul. Rótulos de ramificação indicam suporte de bootstrap. A grade ao longo do lado direito indica as espécies em que cada subfamília aparece: $T$. gondii (Tg), N. caninum (Nc), $S$. neurona $(\mathrm{Sn})$ e E. tenella (Et).

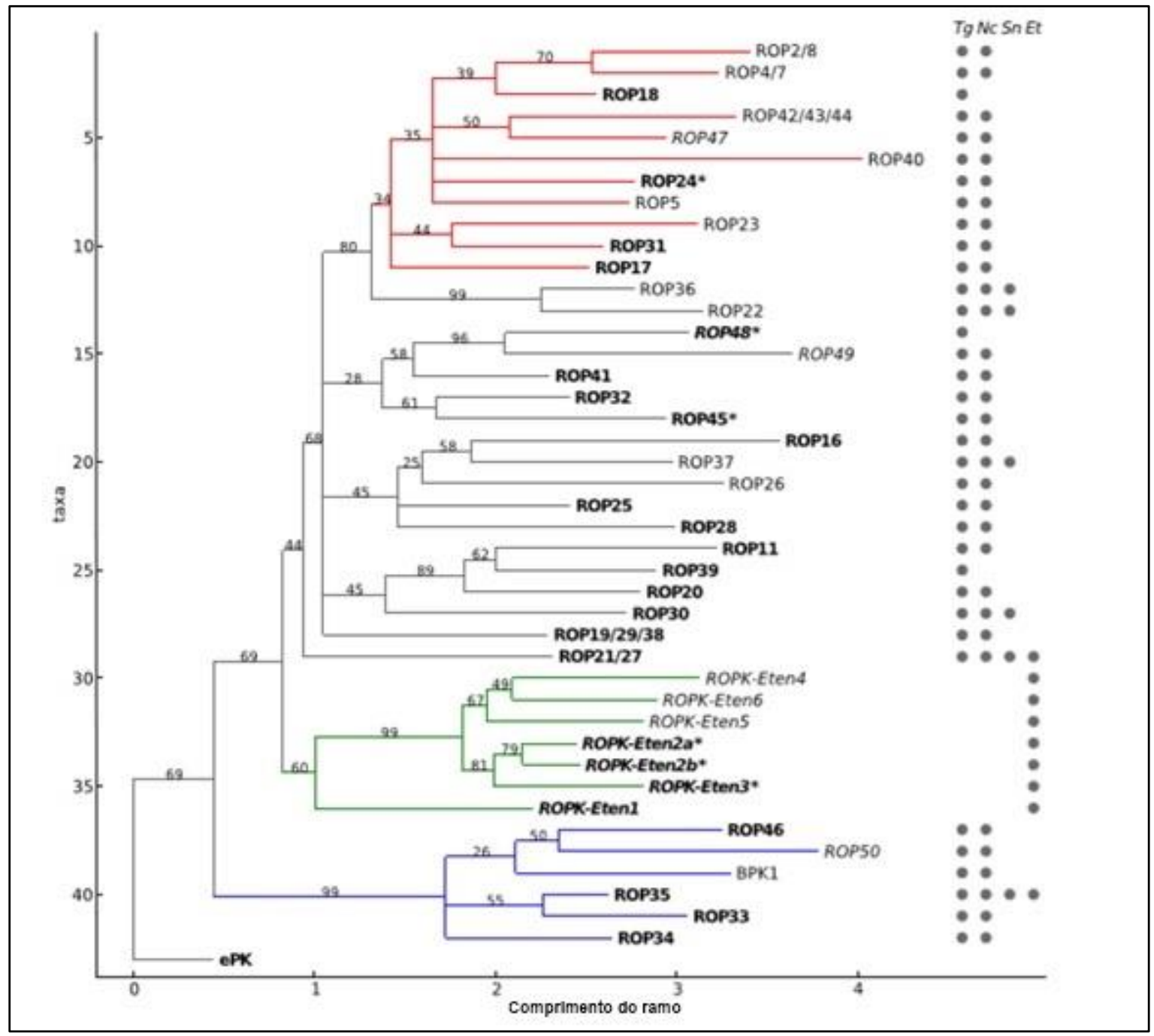

Fonte: Adaptado de Talevich e Kannan (2013).

Apesar do elevado grau de sintenia e conservação das sequências genômicas entre $N$. caninum e $T$. gondii, as regiões de codificação para secreção de fatores de virulência como as ROPs, bem como os seus níveis de expressão, revelaram diferenças consideráveis. Por exemplo, as proteínas ROP5 e ROP16 estão presentes em $N$. caninum e $T$. gondii, mas NcROP18 é um pseudogene em contraste com uma expressão muito ativa de TgROP18 (PEIXOTO et al., 2010). Pseudogenes são definidos como sequencias genômicas de DNA, similares a genes 
codificadores, mas sem potencial codificador, cuja maioria se origina de cópias duplicadas de genes funcionais. (PODLAHA; ZHANG, 2010). Um gene funcional pode também tornar-se um pseudogene sem duplicação, se a sua função não confere uma vantagem ou aptidão para o organismo devido a uma mudança no ambiente ou mutação genética (ZHANG et al., 2010; MARQUES et al., 2012). ROP18 é um fator de virulência determinante de T. gondii que protege o vacúolo parasitário de ataque pelo sistema imunológico do organismo hospedeiro (STEINFELDT et al., 2010). Em $N$. caninum ROP18 é um pseudogene. E recentemente, Ma e colaboradores (2017), desenvolveram um plasmídeo knockout pTCR-CD para editar genes de $N$. caninum e conseguiram detectar alguns papéis de NcROP5, como um grande potencial de virulência, que também é evidenciado em $T$. gondii.

Assim, estudos sugerem um papel reduzido para o fator de virulência de genes ortólogos $T$. gondii em $N$. caninum, por exemplo, em relação às proteínas de virulência associados às proteínas ROP18, ROP16 e ROP5. A perda de função de ROP18 em N. caninum pode estar relacionada a uma ação adaptativa, impedindo a morte de seu hospedeiro e promovendo a sobrevivência do parasito (REID et al., 2012). Portanto, não se espera que todas as ROPKs de $N$. caninum sejam funcionalmente semelhantes em $T$. gondii e vice-versa. De acordo com um estudo in silico, há 68 genes de roptrias presentes tanto em $T$. gondii como $N$. caninum, sendo 61 ortólogos e 7 específicos para cada espécie (REID et al., 2012). A partir de análises do genoma de espécies que pertencem ao filo Apicomplexa foi observado que os genes que codificam as proteínas RON estão conservados na maioria dos parasitos, com exceção da RON8, que é restrita aos coccídios, como $T$. gondii e $N$. caninum (STRAUB et al., 2009).

\subsection{Proteínas de roptrias com potencial fator de virulência em células hospedeiras}

Em $T$. gondii, as proteínas de roptrias mais bem estudadas são as da família das roptrias (ROPK) que inclui proteínas quinases e pseudoquinases com papel fundamental na virulência (LEI et al., 2014; REESE et al., 2014). O grupo de ROPKs foi caracterizado como "kinome", no qual, incialmente foram identificadas 34 proteínas relacionadas a esse conjunto em T. gongii (PEIXOTO el al., 2010). No 
entanto, Fox e colaboradores (2016) relataram que, apesar do papel da maioria das ROPKs na virulência não ter sido testado diretamente, os autores conseguiram extrair importantes conclusões. A partir de análises de estudos com ROP5, ROP17, ROP18, ROP35 e ROP38, foram encontrados dados com influências cruciais sobre as funções necessárias para estabelecer infecção crônica. Dentre elas, as que apresentam funções na fisiologia do parasito mais conhecidas são as ROP5 e ROP18. Apesar dessas proteínas em sua maior parte possuírem sua função desconhecida, sabe-se que grande parte delas é secretada para o citosol da célula hospedeira durante a invasão, sendo que algumas delas podem se associar com a membrana do vacúolo parasitóforo (EL HAJJ et al., 2006; BRADLEY; SIBLEY, 2007; BOOTHROYD \& DUBREMETZ, 2008). Pelo menos 12 membros da família ROP2 compartilham de certo número de características: todos os precursores da família contêm um peptídeo sinal e a maioria deles mantém uma pro região que é clivada durante a maturação (REESE \& BOOTHROYD, 2009). Também apresentam um domínio rico em arginina de 100-150 resíduos e um domínio de quinase C-terminal (EL HAJJ et al., 2006; REESE \& BOOTHROYD, 2009).

No caso de $N$. caninum, a família ROP2 foi recém descrita e há poucos dados disponíveis (TALEVICH; KANNAN, 2013). NcROP1, NcROP2Fam-1, NcROP4, NcROP5, NcROP9, NcROP30 eNcROP40 foram identificadas por estudos de proteômica (MARUGÁN-HERNÁNDEZ et al., 2011; SOHN et al., 2011; REGIDORCERRILLO et al., 2012), sendo que apenas NcROP5 teve a sua função descrita (MA et al., 2017). Ma e colaboradores (2017), analisaram que NcROP5 tem uma baixa patogenicidade e que está intimamente relacionada com TgROP5.Verificaram também que NcROP5 tem uma função associada com virulência do parasito e é bem semelhante nos demais Apicomplexas (GHORBAL et al., 2014; REESE \& BOOTHROYD, 2011; WALZER et al., 2013). Atualmente, as proteínas de roptrias presentes em $N$. caninum que foram parcialmente caracterizadas são NcROP2Fam1 que possui as características dos membros da família ROP2 e aparenta não possuir atividade catalítica (ALAEDDINE et al., 2013) e NcROP40 (PASTORFERNÁNDEZ et al., 2015), esta última já havia sido descrita como sendo mais abundantemente expressa em isolados virulentos de $N$. caninum (REGIDORCERRILLO et al., 2012).

Em vista das observações anteriores, o estudo proposto baseia-se na identificação e caracterização de proteínas de roptrias que são particulares para $N$. 
caninum. O trabalho focou sobre duas proteínas de roptrias: NCLIV_031550 e NCLIV_011700. NCLIV_031550 é classificada na categoria -ROPK (proteína de roptria com domínio quinase) e foi denominada ROP55 (TALEVICH; KANNAN, 2013). Do mesmo modo, a outra proteína, NCLIV_011700 (descrita como ROP15B), foi primeiro identificada por Reid e colegas (2012) como um gene único para $N$. caninum, homóloga de ROP2 com domínio de proteína quinase. NCLIV_031550 (ROP55) e NCLIV_011700 (ROP15B) também foram identificadas em duas abordagens proteômicas que o nosso grupo desenvolveu em N. caninum (POLLOOLIVEIRA et al., 2013). Na fração secretada (ESA), ROP55 e ROP15B representaram as proteínas de roptrias mais prevalentes, aumentando a evidência de que estas são organelas secretoras de proteínas e que possuem uma função relevante em $N$. caninum.

\section{OBJETIVO}

\subsection{Geral}

Caracterizar as proteínas roptrias NCLIV_031550 (ROP55) e NCLIV_011700 (ROP15B) em Neospora caninum.

\subsection{Específicos}

1. Clonagem e expressão dos genes NCLIV_031550 (ROP55) e NCLIV_011700 (ROP15B) de forma heteróloga em E. coli;

2. Produção e purificação das formas recombinantes de NcROP15B e NcROP55 para produção de respectivos anticorpos policlonais;

3. Localizar as proteínas NcROP15B e NcROP55 nativas através de western blot 1D.

4. Investigar a capacidade de inibição da invasão de $N$. caninum por ensaios com anticorpos policlonais anti- NcROP15B, NcROP55 e sua associação;

5. Localizar NcROP15B e NcROP55 em $N$. caninum por imunofluorescência confocal.

\section{MATERIAL E MÉTODOS}

\subsection{Cultivo in vitro e manutenção de taquizoítos}


Existem evidências filogenéticas que as ROPs tem sofrido extensa seleção evolutiva após a divergência entre os gêneros Neospora e Toxoplasma (PEIXOTO et al, 2010), o que tem sido comprovado por diversos trabalhos mostrando diferentes padrões de expressão de ROPs entre os dois parasitos. Desta forma, o nosso trabalho de caracterização das proteínas NcROP15B e NcROP55, mesmo que inicial, é de extrema importância, já que despertou um horizonte para aprofundamento dos estudos, como abordagens funcionais destes genes em $N$. caninum. Genes específicos e ativos podem auxiliar não somente uma melhor compreensão do parasito mas abrir caminhos para identificação de novos alvos terapêuticos de neosporose.

\section{CONCLUSÕES}

- As sequências de NcROP15B e NcROP55 possuem características de proteínas de roptrias quinases;

- NcROP15B possui identidade de 19\% com as sequencias de ROP15 de T. gondii e Hammondia hammondi e NcROP55 é 14\% idêntico com ROP37 de T. gondii e com ROP28 de Hammondia hammondi, e 15\% com ROP28 de Neospora caninum.

- NcROP15B e NcROP55 estão localizadas na região perinuclear de taquizoítos de N. caninum em microscopia confocal;

- Soro policlonal anti-NcROP15B e anti-NcROP55 inibem invasão celular de N.caninum em 12 e $7 \%$, e quando associados a inibição de invasão sobe para $62 \%$ 


\section{REFERÊNCIAS}

AGUIAR, D. M. et al. Prevalence of anti-Neospora caninum antibodies in cattle and dogs from Western Amazon, Brazil, in association with some possible risk factors. Vet Parasitol, v. 142, n.1-2, p.71-77, 2006.

ALAEDDINE, F. et al. Molecular cloning and characterization of NcROP2Fam-1, a member of the ROP2 family of rhoptry proteins in Neospora caninum that is targeted by antibodies neutralizing host cell invasion in vitro. Parasitology, v. 140, n. 8, p. 1033-50, 2013.

ALEXANDER, D. L. et al. Identification of the moving junction complex of Toxoplasma gondii: A collaboration between distinct secretory organelles. PLoS Pathogens, v. 1, n. 2, p. 0137-0149, 2005.

ANDRÉ, M. R. et al. Antibodies to Toxoplasma gondii and Neospora caninum in captive neotropical and exotic wild canids and felids. J Parasitol, v. 96, n. 5, p. 10071009, 2010.

BARR ,B. C. et al Congenital Neospora infection in calves born from cows that had previously aborted Neospora-infected fetuses: four cases (1990-1992). J Am Vet Med Assoc, v. 202, p. 113-117,1993.

BARRATT, J. L. et al. Importance of nonenteric protozoan infections in immunocompromised people. Clinical Microbiology Reviews, v. 23, n. 4, p. 795836, 2010.

BAUM, J. et al. Regulation of apicomplexan actin-based motility. Nature reviews. Microbiology, v. 4, n. 8, p. 621-628, 2006.

BENETTI, A. H. et al. Pesquisa de anticorpos anti-Neospora caninum em bovinos leiteiros, cães e trabalhadores rurais da região Sudoeste do Estado de Mato Grosso. Rev Bras Parasitol Vet; v. 18 (Suppl 1), p. 29-33, 2009.

BESTEIRO, S. Toxoplasma control of host apoptosis: the art of not biting too hard the hand that feeds you. Microbial Cell, v. 2, n. 6, p. 178-181, 2015.

BESTEIRO, S. et al. Export of a Toxoplasma gondii rhoptry neck protein complex at the host cell membrane to form the moving junction during invasion. PLoS Pathog, $v$. 5, e1000309, 2009.

BILLKER, O.; LOURIDO, S.; SIBLEY, L. D. Calcium-Dependent Signaling and Kinases in Apicomplexan Parasites. Cell Host and Microbe, v. 5, n. 6, p. 612-622, 2009.

BJERKÅS, I.; MOHN, S. F.; PRESTHUS, J. Unidentified cyst-forming sporozoon causing encephalomyelitis and myositis in dogs. Zeitschrift fur Parasitenkunde (Berlin, Germany), v. 70, n. 2, p. 271-274, 1984.

BLADER, I. J., SAEIJ, J. P. Communication between Toxoplasma gondii and its host: impact on parasite growth, development, immune evasion, and virulence. APMIS : acta pathologica, microbiologica, et immunologica Scandinavica, v.117, n. 5-6, p. 458-476, 2009. 
BOOTHROYD, J. C.; DUBREMETZ, J.-F. Kiss and spit: the dual roles of Toxoplasma rhoptries. Nature Reviews Microbiology, v. 6, n. 1, p. 79-88, 2008.

BRADLEY, P. J.; SIBLEY, L. D. Rhoptries: an arsenal of secreted virulence factors. Current Opinion in Microbiology, v. 10, n. 6, p. 582-587, 2007.

BRECHT, S., CARRUTHERS, V.B., FERGUSON, D.J., GIDDINGS, O.K., WANG, G., JAKLE, U., HARPER, J.M., SIBLEY, L.D., SOLDATI, D. The toxoplasma micronemal protein MIC4 is an adhesin composed of six conserved apple domains. J Biol Chem 276: p. 4119-4127, 2001.

BURG, J. L. et al. Molecular analysis of the gene encoding the major surface antigen of Toxoplasma gondii. Information about subscribing to The Journal of Immunology, 1988.

CARDOSO, J. M. S et al. Neospora caninum: analysis of reproductive parameters in dairy herds in Brazil. Braz J Vet Res Anim Sci, v. 49, n. 6, p. 459-464, 2012.

CARRUTHERS, V. B.; SIBLEY, L. D. Mobilization of intracellular calcium stimulates microneme discharge in Toxoplasma gondii. Molecular Microbiology, v. 31, n. 2, p. 421-428, 1999.

CARRUTHERS, V. B.; TOMLEY, F. M. Microneme proteins in apicomplexans. Subcellular biochemistry, v. 47, p. 33-45, 2008.

CARRUTHERS, V.; BOOTHROYD, J. C. Pulling together: an integrated model of Toxoplasma cell invasion. Current Opinion in Microbiology, v. 10, n. 1, p. 83-89, 2007.

CESBRON-DELAUW, M. F. et al. Similarities between the primary structures of two distinct major surface proteins of Toxoplasma gondii. Journal of Biological Chemistry, v. 269, n. 23, p. 16217-16222, 1994.

COSTA, K. S. et al. Chickens (Gallus domesticus) are natural intermediate hosts of Neospora caninum. Int J Parasitol, v. 38, v. 2, p. 157-159, 2008.

DECOTE-RICARDO, D., NUNES, M. P., MORROT, A., FREIRE-DE-LIMA, C. G. Implication of Apoptosis for the Pathogenesis of Trypanosoma cruzi Infection. Frontiers in Immunology, v. 8, 518, 2017.

DOERIG, C. et al. Malaria: Targeting parasite and host cell kinomes. Biochimica et Biophysica Acta (BBA) - Proteins and Proteomics, v. 1804, n. 3, p. 604-612, 2010.

DONAHOE, S. L. et al. A review of neosporosis and pathologic findings of Neospora caninum infection in wildlife. International Journal for Parasitology: Parasites and Wildlife, v. 4, n. 2, p. 216-38, 2015.

DUBEY, J. P. Neosporosis in cattle: biology and economic impact. J. Am. Vet. Med. Assoc., v. 214, p.1160-1163, 1999.

DUBEY, J. P. History of the discovery of the life cycle of Toxoplasma gondii. International Journal for Parasitology, v. 39, n. 8, p. 877-882, 2009. 
DUBEY, J.P. et al. Newly recognized fatal protozoan disease of dogs. J Am Vet Med Assoc, v.192, p. 1269-1285, 1988.

DUBEY, J.P.; KOESTNER, A; PIPER, R.C. Repeated transplacental transmission of Neospora caninum in dogs. J Am Vet Med Assoc, v. 197, p. 857-860, 1990.

DUBEY, J. P. et al. Redescription of Neospora caninum and its differentiation from related coccidia. International Journal for Parasitology, v. 32, n. 8, p. 929-946, 2002.

DUBEY, J. P.; DUBEY, J. Review of Neospora caninum and neosporosis in animals. The Korean journal of parasitology, v. 41, n. 1, p. 1-16, 2003.

DUBEY, J. P.; LINDSAY, D. S.; SPEER, C. A. Structures of Toxoplasma gondii tachyzoites, bradyzoites, and sporozoites and biology and development of tissue cysts. Clinical microbiology reviews, v. 11, n. 2, p. 267-99, 1998.

DUBEY, J. P.; SCHARES, G. Neosporosis in animals-The last five years. Veterinary Parasitology, v. 180, n. 1-2, p. 90-108, 2011.

EL HAJJ, H. et al. The ROP2 family of Toxoplasma gondii rhoptry proteins: Proteomic and genomic characterization and molecular modeling. Proteomics, v. 6, n. 21, p. 5773-5784, 2006.

ETHERIDGE, R. D. et al. The Toxoplasma pseudokinase ROP5 forms complexes with ROP18 and ROP17 kinases that synergize to control acute virulence in mice. Cell Host Microbe. 2014 May 14; 15(5):537-50

FENTRESS, S. J. et al. Phosphorylation of immunity-related GTPases by a Toxoplasma gondii-secreted kinase promotes macrophage survival and virulence. Cell Host Microbe. n. 8, p.484-495, 2010.

FINN, D.R., et al. InterPro in 2017 - beyond protein family and domain annotations. Nucleic Acids Research, Jan, 2017.

FILHO, P. C. G. A, et al. Incidence and vertical transmission rate of Neospora caninum in sheep. Comp Immunol Microbiol Infect Dis, v. 52, p. 19-22, 2017

FRENAL, K. et al. Functional dissection of the apicomplexan glideosome molecular architecture. Cell Host and Microbe, v. 8, n. 4, p. 343-357, 2010.

GARCÍA-FRUITÓS, E. Inclusion bodies: a new concept. Microbial Cell Factories, v. 9, p. 80, 2010.

GENNARI, S. M et al. Occurrence of anti-Neospora caninum antibodies in water buffaloes (Bubalus bubalis) from the northern region of Brazil. Vet Parasitol, v. 134, n. 1-2, p. 169-171, 2005.

GHORBAL, M. et al. Genome editing in the human malaria parasite Plasmodium falciparum using the CRISPR-Cas9 system. Nat. Biotechnol, v. 32, p. 819-821, 2014.

GONDIM, L. F. P; PINHEIRO A. M. , ALMEIDA, M. A. O. Frequência de anticorpos anti-Neospora caninum em búfalos (Bubalus bubalis) criados no estado da Bahia. 
Rev Bras Saúde Prod Anim, v. 8, n.2, p. 92-96, 2007.

GONDIM, L. S. Q, et al. Toxoplasma gondii and Neospora caninum in sparrows (Passer domesticus) in the Northeast of Brazil. Vet Parasitol, v. 168, n. 1-2, p. 121124, 2010.

GOODSWEN, S.J.; KENNEDY, P.J.; ELLIS, J.T. A review of the infection, genetics, and evolution of Neospora caninum: From the past to the present. Infection, Genetics and Evolution, v.13, p.133-150, 2013.

GUIDO, S. et al. Serology-Based Diagnostics for the Control of Bovine Neosporosis. Trends in Parasitology, v.32, n. 2, p. 131-143, 2016.

HAJAGOS, B. E. et al. Molecular dissection of novel trafficking and processing of the Toxoplasma gondii rhoptry metalloprotease toxolysin-1. Traffic. n. 13, p .292-304, 2012.

HÅKANSSON, S.; CHARRON, A J.; SIBLEY, L. D. Toxoplasma evacuoles: a twostep process of secretion and fusion forms the parasitophorous vacuole. The EMBO journal, v. 20, n. 12, p. 3132-44, 2001.

HALDORSON, G. J. et al. Neospora caninum: Antibodies directed against tachyzoite surface protein NcSRS2 inhibit parasite attachment and invasion of placental trophoblasts in vitro. Experimental Parasitology, v. 112, n. 3, p. 172-178, 2006.

HAMMOUDI, P. et al, 2015. Fundamental roles of the golgi-associated Toxoplasma aspartyl protease, ASP5, at the host-parasite interface. PLoS Pathog, v. 11, e1005211, 2015.

HANKS, S.K.; HUNTER, T. Protein kinases 6. The eukaryotic protein kinase superfamily: kinase (catalytic) domain structure and classification. FASEB J. v. 9 n.857696, maio, 1995

HARRISON, J.; MATSON, P. Patterns and controls of nitrous oxide emissions from waters draining a subtropical agricultural valley. Global Biogeochemical Cycles, v. 17, n. 3, p. n/a-n/a, 2003.

HEHL, A.; KRIEGER, T.; BOOTHROYD, J. C. Identification and characterization of SRS1, a Toxoplasma gondii surface antigen upstream of and related to SAG11. Molecular and Biochemical Parasitology, v. 89, n. 2, p. 271-282, 1997.

HEMPHILL, A.; GOTTSTEIN, B.; KAUFMANN, H. Adhesion and invasion of bovine endothelial cells by Neospora caninum. Parasitology, v. 112 (Pt 2), 183-197, 1996.

HEMPHILL, A. et al. Proteins mediating the Neospora caninum-host cell interaction as targets for vaccination. Frontiers in bioscience (Elite edition), v. 5, n. December 2015, p. 23-36, 2013.

HEMPHILL, A.; VONLAUFEN, N.; NAGULESWARAN, A. Cellular and immunological basis of the host-parasite relationship during infection with Neospora caninum. Parasitology, v. 133, n. 3, p. 261-278, 2006.

HERMANNS, T. The Toxoplasma gondii rhoptry protein ROP18 is an Irga6-specific kinase and regulated by the dense granule protein GRA7. Cellular Microbiology. 
v.18, n. 2, p. 244-259, 2016.

HIETALA, S. K.; THURMOND, M. C. Postnatal Neospora caninum transmission and transient serologic responses in two dairies. International Journal for Parasitology, v. 29, p. 1669-1676, 1999.

HUI, W., et al. A nuclear factor of high mobility group box protein in Toxoplasma gondii. PLoS One 9, e111993, 2014.

INNES, E.A. The host-parasite relationship in pregnant cattle infected with Neospora caninum. Parasitology, v.134, p.1903-1910, 2007.

JACOT, D., SOLDATI-FAVRE, D. Does protein phosphorylation govern host cell entry and egress by the Apicomplexa?. Int J Med Microbiol. v. 302, p.195-202, 2012.

JUFVAS, Å., STRÅlFORS, P.; VENER, A. V. Histone Variants and Their PostTranslational Modifications in Primary Human Fat Cells. PLoS ONE. v. 6, n. 1, 2011.

KEMP, L. E.; YAMAMOTO, M.; SOLDATI-FAVRE, D. Subversion of host cellular functions by the apicomplexan parasites. FEMS Microbiology Reviews, v. 37, n. 4, p. 607-631, 2013.

KHAMINETS, A. et al. Coordinated loading of IRG resistance GTPases on to the Toxoplasma gondii parasitophorous vacuole. Cell Microbiol. n.12, p. 939-961, 2010.

LANGONI, $\mathrm{H}$. et al. Prevalence of antibodies against Toxoplasma gondii and Neospora caninum in dogs. Braz J Microbiol, v. 44, n. 4, p. 1327-1330, 2014.

LEI, T. et al. ROP18 is a key factor responsible for virulence difference between Toxoplasma gondii and Neospora caninum. PLoS ONE, v. 9, n. 6, p. 1-10, 2014.

LEINEWEBER, M., SPEKKER-BOSKER, K., INCE, V., SCHARES, G., HEMPHILL, A., ELLER, S. K., DÄUBENER, W. First Characterization of the Neospora caninum Dense Granule Protein GRA9. BioMed Research International, 2017.

LEMGRUBER, L. et al. New details on the fine structure of the rhoptry of Toxoplasma gondii. Microscopy Research and Technique, v. 74, n. 9, p. 812-818, 2011.

LI, M., et al. The apoptotic role of metacaspase in Toxoplasma gondii. Front. Microbiol. 6, 2016.

LIM, D.C. et al. Toxoplasma and Plasmodium protein kinases: roles in invasion and host cell remodelling. International Journal for Parasitology. v. 42, p. 21-32, 2012.

MA, L. et al. Q. Rhoptry protein 5 (ROP5) Is a Key Virulence Factor in Neospora caninum. Frontiers in Microbiology. 8:370, 2017.

MA, L. et al. A ROP16 de Neospora caninum desempenha um papel importante na patogenicidade por fosforilação da célula hospedeira STAT3. Parasitologia veterinária, n. 243 , p. 135-147, 2017.

MACÊDO, A. G. et al. SAG2A protein from Toxoplasma gondii interacts with both 
innate and adaptive immune compartments of infected hosts. Parasites \& vectors, v. 6, p. $163,2013$.

MARK, A.; CHEADLE, J.R A. S.; BYRON, L. Seroprevalences of Neospora caninum and Toxoplasma gondii in Nondomestic Felids from Southern Africa. Blagburn Source. Journal of Zoo and Wildlife Medicine , v. 30, n. 2, jun, p. 248-251, 1999.

MARQueS, A. C., TAN, J., LEE, S., KONG, L., HEGER, A., PONTING, C. P. Evidence for conserved post-transcriptional roles of unitary pseudogenes and for frequent bifunctionality of mRNAs. Genome Biol. v. 13, 2012.

MARUGÁN-HERNÁNDEZ, V. et al. Identification of novel rhoptry proteins in Neospora caninum by LC/MS-MS analysis of subcellular fractions. Journal of proteomics, v. 74, n. 5, p. 629-42, 2011.

MCALLISTER, M. M., et al. Dogs are definitive hosts of Neospora caninum. International Journal for Parasitology, v. 28, n. 9, p. 1473-1478, 1998.

MOLESTINA, R. E.; SINAI, A. P. Host and parasite-derived IKK activities direct distinct temporal phases of NF-kappaB activation and target gene expression following Toxoplasma gondii infection. Journal of cell science, v. 118, n. Pt 24, p. 5785-96, 2005.

MOLESTINA, R. E.; SINAI, A. P. Detection of a novel parasite kinase activity at the Toxoplasma gondii parasitophorous vacuole membrane capable of phosphorylating host lkappaBalpha. Cellular microbiology, v. 7, n. 3, p. 351-62, 2005b.

MONNEY, T.; DEBACHE, K.; HEMPHILL, A. Vaccines against a Major Cause of Abortion in Cattle, Neospora caninum Infection. Animals, v. 1, n. 4, p. 306-325, 2011.

MONTOYA, J. G.; LIESENFELD, O. Toxoplasmosis. Lancet, v. 363, n. 9425, p. 1965-1976, 2004.

NATALIE, A. et al. Plasmodium rhoptry proteins: why order is important, Trends in Parasitology, v. 29, n. 5, p. 228-236, 2013.

NICHOLAS, K.B.; NICHOLAS H.B. JR.; AND DEERFIELD, D.W. II. GeneDoc: analysis and visualization of genetic variation. EMBNEW.NEWS, v. 4, n. 14, 1997.

NISHIKAWA, Y. et al. Monoclonal antibody inhibition of Neospora caninum tachyzoite invasion into host cells. International Journal for Parasitology, v. 30, n. 1 , p. 51-58, 2000.

NISHIKAWA, Y. et al. Characterization of Neospora caninum surface protein NcSRS2 based on baculovirus expression system and its application for serodiagnosis of Neospora infection. Journal of Clinical Microbiology, v. 39, n. 11, p. 3987-3991, 2001.

ONG, Y. C.; REESE, M. L.; BOOTHROYD, J. C. Toxoplasma Rhoptry Protein 16 (ROP16) subverts host function by direct tyrosine phosphorylation of STAT6. Journal of Biological Chemistry, v. 285, n. 37, p. 28731-28740, 2010.

PARMLEY, S. F. et al. Expression, characterization, and serologic reactivity of 
recombinant surface antigen P22 of Toxoplasma gondii. Journal of Clinical Microbiology, v. 30, n. 5, p. 1127-1133, 1992.

PASTOR-FERNÁNDEZ, I. A. et al. Characterization of the Neospora caninum NcROP40 and NcROP2Fam-1 rhoptry proteins during the tachyzoite lytic cycle. Parasitology, p. 97-113, 2015.

PASTOR-FERNÁNDEZ, I. et al. Characterization of the Neospora caninum NcROP40 and NcROP2Fam-1 rhoptry proteins during the tachyzoite lytic cycle. Parasitology. v. 143, n.1, p. 97-113, 2016.

PEIXOTO, L. et al. Integrative genomic approaches highlight a family of parasitespecific kinases that regulate host responses. Cell Host Microbe, v. 8, p. 208-218, 2010.

PEREIRA, L. M.; BARONI, L.; YATSUDA, A. P. Experimental Parasitology A transgenic Neospora caninum strain based on mutations of the dihydrofolate reductase - thymidylate synthase gene. Experimental Parasitology, v. 138, p. 4047, 2014.

PIERGILI FIORETTI, D.; PASQUALI, P.; DIAFERIA, M.; MANGILI, V.; ROSIGNOLI, L. Neospora caninum infection and congenital transmission: serological and parasitological study of cows up to the fourth gestation. Journal of Veterinary medicine B Infectious diseases and Veterinary Public Health. v. 50(8), p.399404, 2003

PODLAHA O.; ZHANG, J. Pseudogenes and their evolution. In: Encyclopedia of Life Sciences. Chichester, UK: John Wiley \& Sons; p. 1-8, 2010.

POLLO-OLIVEIRA, L. et al. Unravelling the Neospora caninum secretome through the secreted fraction (ESA) and quantification of the discharged tachyzoite using high-resolution mass spectrometry-based proteomics. Parasites \& vectors, v. 6, n. 1, p. 335, 2013.

PUNTA, M. et al. The Pfam protein families database. Nucleic Acids Research, v. 40, p. D290-301, 2012

RAIMUNDO, J. M., et al. Toxoplasma gondii and Neospora caninum in dogs from the state of Tocantins: serology and associated factors. Rev Bras Parasitol Vet, v.24, n.4, p. 475-481, 2015.

RAMOS, I.A.S., SILVA, R.J., MACIEL, T.A., SILVA, J.A.B.A., FIDELIS, O.L., SOARES, P.C., et al. Assessment of transplacental transmission of Neospora caninum in dairy cattle in the Agreste region of Pernambuco. Rev Bras Parasitol Vet 2016; 25(4): 516-522.

RAVINDRAN, S., BOOTHROYD, J. C. Secretion of Proteins into Host Cells by Apicomplexan Parasites. Traffic. v.9, p. 647-656, 2008.

REESE, M. L.; BOOTHROYD, J. C. A helical membrane-binding domain targets the Toxoplasma ROP2 family to the parasitophorous vacuole. Traffic, v. 10, n. 10, p. 1458-1470, 2009. 
REESE, M. L.; SHAH; BOOTHROYD, J. C. The Toxoplasma pseudokinase ROP5 is an allosteric inhibitor of the immunity-related GTPases. Journal of Biological Chemistry, v. 289, n. 40, p. 27849-27858, 2014.

REGIDOR-CERRILLO, J. et al. Proteome expression changes among virulent and attenuated Neospora caninum isolates. Journal of Proteomics, v. 75, n. 8, p. 23062318, 2012.

REICHEL, M. P.; ELLIS, J. T.; DUBEY, J. P. Neosporosis and hammondiosis in dogs. Journal of Small Animal Practice, v. 48, n. 6, p. 308-312, 2007.

REID, A. J. et al. Comparative genomics of the apicomplexan parasites Toxoplasma gondii and Neospora caninum: Coccidia differing in host range and transmission strategy. PLoS Pathogens, v. 8, n. 3, p. e1002567, 2012.

RENSLO, A. R.; MCKERROW, J. H. Drug discovery and development for neglected parasitic diseases. Nature Chemical Biology, v. 2, n. 12, p. 701-710, 2006.

ROCCHI, M. S. et al. Selection of Neospora caninum antigens stimulating bovine CD4+ve $\mathrm{T}$ cell responses through immuno-potency screening and proteomic approaches. Veterinary Research, v. 42, n. 1, p. 91, 2011.

SCHARES, G. et al. The efficiency of vertical transmission of Neospora caninum in dairy cattle analyzed by serological techniques. Vet Parasitol, v. 80, p. 87-98, 1998.

SICUPIRA, P. M. L. et al. Factors associated with infection by Neospora caninum in dogs in Brazil. Vet Parasitol, v. 185, n. 2-4, p. 305-308, 2012.

SHEN, B. et al. Efficient gene disruption in diverse strains of Toxoplasma gondii using CRISPR/CAS9. MBIO 5, e1114, 2014.

SOARES, H. S. et al. Occurrence of antibodies against Neospora caninum in wild pigs (Sus scrofa) in the Pantanal, Mato Grosso do Sul, Brazil. Braz J Vet Res Anim Sci, v. 53, n. 1, p. 112-116, 2016.

SOHN, C. S. et al. Identification of novel proteins in Neospora caninum using an organelle purification and monoclonal antibody approach. PLoS ONE, v. 6, n. 4, p. 1$12,2011$.

SANTOS, J. M.; GRAINDORGE, A., SOLDATI-FAVRE, D. New insights into parasite rhomboid proteases. Molecular \& Biochemical Parasitology, v. 182, p. 27-36, 2012.

SNAK, A. et al. Neospora caninum in properties in the west region of Paraná, Brazil: prevalence and risk factors. Rev. Bras. Parasitol. Vet., Jaboticabal, v. 27, n. 1, p. 51-59, Mar., 2018.

STEINFELDT, T. et al.. Phosphorylation of mouse immunity-related gtpase (IRG) resistance proteins is an evasion strategy for virulent Toxoplasma gondii. PLoS Biology, v. 8, n. 12, 2010.

TAKASHIMA, Y. et al. Prevalence and dynamics of antibodies against NcSAG1 and NcGRA7 antigens of Neospora caninum in cattle during the gestation period. J. Vet. Med. Sci. v. 75, p.1413-1418, 2013. 
TALEVICH, E.; KANNAN, N. Structural and evolutionary adaptation of rhoptry kinases and pseudokinases, a family of coccidian virulence factors. BMC evolutionary biology, v. 13, n. 1, p. 117, 2013.

TALEVICH, E.; MIRZA, A.; KANNAN, N. Structural and evolutionary divergence of eukaryotic protein kinases in Apicomplexa. BMC Evolutionary Biology, v. 11, n. 1, p. 321, 2011.

TIRICHINE, L. et al. Marine Genomics Histone extraction protocol from the two model diatoms Phaeodactylum tricornutum and Thalassiosira pseudonana. v. 13, p. 21-25, 2014.

TRELLE, M. B. et al. Global Histone Analysis by Mass Spectrometry Reveals a High Content of Acetylated Lysine Residues in the Malaria Parasite Plasmodium falciparum research articles. p. 3439-3450, 2009.

WALLACH, M. Role of antibody in immunity and control of chicken coccidiosis. Trends in Parasitology, v. 26, n. 8, p. 382-387, 2010.

WALZER,K. A. et al. Hammondia hammondi, an avirulent relative of Toxoplasma gondii, has functional orthologs of known T. gondii virulence genes. Proc. Natl. Acad. Sci. U.S.A., v. 110, p. 7446-7451, 2013.

WILLIAMS, M.J. Two essential light chains regulate the MyoA lever arm to promote Toxoplasma gliding motility. mBio, v. 6, p. e815-e845, 2015.

ZHANG, Z.D.,et al. Identification and analysis of unitary pseudogenes: historic and contemporary gene losses in humans and other primates. Genome Biol, 2010.

ZHANG, K. et al. ScienceDirect Comparative analysis of histone $\mathrm{H} 3$ and $\mathrm{H} 4$ posttranslational modifications of esophageal squamous cell carcinoma with different invasive capabilities. Journal of Proteomics, v. 112, p. 180-189, 2014. 